Research

Open Access

\title{
Danaparoid sodium inhibits systemic inflammation and prevents endotoxin-induced acute lung injury in rats
}

\author{
Satoshi Hagiwara, Hideo Iwasaka, Seigo Hidaka, Sohei Hishiyama and Takayuki Noguchi
}

\author{
Department of Brain and Nerve Science, Anesthesiology, Oita University Faculty of Medicine, Oita, Japan \\ Corresponding author: Satoshi Hagiwara, saku@med.oita-u.ac.jp \\ Received: 27 Nov 2007 Revisions requested: 16 Jan 2008 Revisions received: 5 Feb 2008 Accepted: 2 Apr 2008 Published: 2 Apr 2008 \\ Critical Care 2008, 12:R43 (doi:10.1186/cc6851) \\ This article is online at: http://ccforum.com/content/12/2/R43 \\ (c) 2008 Hagiwara et al.; licensee BioMed Central Ltd. \\ This is an open access article distributed under the terms of the Creative Commons Attribution License (http://creativecommons.org/licenses/by/2.0), \\ which permits unrestricted use, distribution, and reproduction in any medium, provided the original work is properly cited.
}

\begin{abstract}
Introduction Systemic inflammatory mediators, including high mobility group box 1 (HMGB1), play an important role in the development of sepsis. Anticoagulants, such as danaparoid sodium (DA), may be able to inhibit sepsis-induced inflammation, but the mechanism of action is not well understood. We hypothesised that DA would act as an inhibitor of systemic inflammation and prevent endotoxin-induced acute lung injury in a rat model.
\end{abstract}

Methods We used male Wistar rats. Animals in the intervention arm received a bolus of $50 \mathrm{U} / \mathrm{kg}$ of DA or saline injected into the tail vein after lipopolysaccharide (LPS) administration. We measured cytokine (tumour necrosis factor (TNF) $\alpha$, interleukin (IL)-6 and IL-10) and HMGB1 levels in serum and lung tissue at regular intervals for $12 \mathrm{~h}$ following LPS injection. The mouse macrophage cell line RAW 264.7 was assessed following stimulation with LPS alone or concurrently with DA with identification of HMGB1 and other cytokines in the supernatant.

Results Survival was significantly higher and lung histopathology significantly improved among the DA (50 U/kg) animals compared to the control rats. The serum and lung HMGB1 levels were lower over time among DA-treated animals. In the in vitro study, administration of DA was associated with decreased production of HMGB1. In the cell signalling studies, $\mathrm{DA}$ administration inhibited the phosphorylation of $I_{\kappa} \mathrm{B}$.

Conclusion DA decreases cytokine and HMGB1 levels during LPS-induced inflammation. As a result, DA ameliorated lung pathology and reduces mortality in endotoxin-induced systemic inflammation in a rat model. This effect may be mediated through the inhibition of cytokines and HMGB1.

\section{Introduction}

Despite extensive investigation of strategies for treating acute lung injury $(A L I)$, the overall mortality still remains high at approximately 30 to $50 \%$ [1]. One of the mechanisms of sepsis-induced acute lung injury involves bacterial endotoxin release into the circulation that activates interconnected inflammatory cascades in the lung, ultimately leading to lung damage $[2,3]$. The production of inflammatory mediators plays an important role in the pathophysiology of inflammation in lung injury.

High mobility group box 1 (HMGB1) protein is an intranuclear protein that was originally identified as a DNA-binding protein, [4], but is also a late-phase mediator in the pathogenesis of sepsis [5]. HMGB1 acts as a pro-coagulant [6], thereby enhancing the inflammatory response in septic shock $[7,8]$. The timing of its release and action is typically later than other cytokines, such as TNF $\alpha$ and IL-1 $\beta$ [5]. Inhibitors of HMGB1 might therefore be beneficial in the treatment of various inflammatory diseases.

The role of clotting factors as inflammatory mediators has attracted close attention. Initiation of the coagulation cascade and the subsequent production of proinflammatory cytokines (particularly in response to factor $\mathrm{Xa}(\mathrm{FXa})$ ) are central to the pathogenesis of sepsis $[9,10]$. Danaparoid sodium (DA) is a low molecular weight heparinoid consisting of heparan sulfate, dermatan sulfate and chondroitin sulfate that has both anticoagulant and anti-inflammatory effects. DA inhibits of FXa and factor Ila (Flla) at ratios greater than heparin, while enacting minimal effects on platelet function [11-13]. Anti-inflammatory and anticoagulant agents have thus become a focus of new treatments for sepsis [14,15].

We hypothesised that DA would act as an inhibitor of systemic inflammation and prevent acute lung injury in a rat model. To

$\mathrm{ALI}=$ acute lung injury; $\mathrm{ARDS}=$ acute respiratory distress syndrome; $\mathrm{DA}=$ danaparoid sodium; $\mathrm{Flla}=$ factor Ila; $F \mathrm{Fa}=$ factor $\mathrm{Xa} ; \mathrm{HMGB} 1=\mathrm{high}$ mobility group box $1 ; \mathrm{IKK}=\mathrm{IkB}$ kinase; LPS = lipopolysaccharide; NF-kB = nuclear factor $\mathrm{kB}$. 
test this hypothesis, we investigated the impact of DA administration on serum and lung levels of HMGB1, serum cytokine levels and on lung histopathology in rats with lipopolysaccharide (LPS)-induced systemic inflammation. To further elucidate the mechanism of action of these effects, we assessed the impact of DA on HMGB1 and cytokine secretion by RAW264.7 cells.

\section{Materials and methods In vivo study}

Materials

Danaparoid sodium was purchased from Organon Co. Ltd. (CC, Oss, The Netherlands). Lipopolysaccharide (LPS, O127:B8) was obtained from Sigma (St Louis, MO, USA). Antibodies to rabbit polyclonal lgE anti-HMGB1 were purchased from Becton Dickinson and Company (Franklin Lakes, NJ, USA). Antibodies to $\beta$-actin were obtained from Abcam PLC (Cambridge, UK).

\section{Treatment protocol}

The study was approved by the Ethical Committee of Animal Research at the College of Medicine, Oita University, Oita, Japan. Male Wistar rats weighing 250 to 300 g (Kyudou, Saga, Japan) were used. Anaesthesia was induced by $4 \%$ sevoflurane. The animals were randomly assigned to one of three groups: (1) untreated LPS group: rats received a bolus of a $0.9 \% \mathrm{NaCl}$ solution $(1.0 \mathrm{ml} / \mathrm{kg})$ and LPS $(7.5 \mathrm{mg} / \mathrm{kg})$ into the tail vein; (2) DA-treated LPS group: rats received a bolus of DA (50 U/ $\mathrm{kg}$ ), and LPS $(7.5 \mathrm{mg} / \mathrm{kg})$ into the tail vein; (3) Negative control group: rats received a bolus of $0.9 \% \mathrm{NaCl}$ solution $(1.0 \mathrm{ml} / \mathrm{kg})$ into the tail vein. Before and after surgery, animals had unlimited access to food and water.

\section{Histological analysis}

A pathologist blind to group assignment analysed the samples and determined levels of lung injury according to Murakami's technique [16]. Briefly, 24 areas in the lung parenchyma were graded on a scale of 0 to 4 ( 0 , absent and appears normal; 1 , light; 2, moderate; 3 , strong; 4, intense) for congestion, oedema, infiltration of inflammatory cells, and haemorrhaging.

\section{Measurements of cytokine and HMGB1 secretion}

HMGB1, II-6 and TNF $\alpha$ levels were determined using a commercial enzyme-linked immunosorbent assay kit. HMGB1 was from Shino-Test Corporation, Tokyo, Japan; IL-6, IL-10 and TNF $\alpha$ were from R\&D Systems Inc, Minneapolis, MN, USA.

\section{Western blotting}

Proteins were subjected to SDS-PAGE, and then transferred to polyvinylidene difluoride (PVDF) membranes (Millipore, Bedford, MA, USA). The membranes were incubated with primary antibody (1:1,000 dilution). After incubation with secondary antibody, blots were developed using an enhanced chemiluminescence detection kit (Amersham, Buckinghamshire, UK) and exposed on Hyperfilm ECL (Amersham). We used the NIH ImageJ software (National Institutes of Health, Bethesda, MD, USA) to quantitate protein band concentrations.

\section{Cell culture study}

The murine macrophage cell line, RAW264.7, was maintained in RPMI 1640 medium containing 5\% heat-inactivated foetal bovine calf serum and antibiotics at $37^{\circ} \mathrm{C}$ under $5 \% \mathrm{CO}_{2}$. The medium was removed and replaced with RPMI 1640 containing $5 \%$ fetal bovine serum (FBS) for most experiments, or Opti-MEM (Sigma) for experiments designed to measure HMGB1 in conditioned media.

\section{Nuclear factor (NF)- $\kappa$ B binding assay}

The DNA binding activity of NF-kB (p50/p65) was determined using an ELISA-based non-radioactive NF- $\kappa B$ p50/p65 transcription factor assay kit (Chemicon, Temecula, CA).

\section{Statistical analysis}

For descriptive purposes, all continuous data were presented as mean \pm SD. The data were analysed by Mann-Whitney $U$ test for comparison between two independent groups. A $p$ value of less than 0.05 was considered to be statistically significant. Survival data were analysed with the Kaplan-Meier program included in the Prism 4.0 software package (San Diego, CA, USA). $p$ Values less than 0.05 were considered statistically significant.

\section{Results \\ In vivo study \\ Mortality}

A total of $40 \%$ of the rats in the untreated LPS group died within $12 \mathrm{~h}$, and an additional 30\% died within $24 \mathrm{~h}$, while all rats in the DA-treated LPS group $(50 \mathrm{U} / \mathrm{kg}$ ) survived (Figure 1). In addition, only $20 \%$ of rats treated with $1 \mathrm{U} / \mathrm{kg} \mathrm{DA}$ and $50 \%$ of rats treated with $10 \mathrm{U} / \mathrm{kg}$ DA survived for $24 \mathrm{~h}$, suggesting a dose-dependent effect of DA on the survival rate of LPS-treated rats (data not shown). All of the saline-treated control animals survived for 7 days. Kaplan-Meier analysis revealed a significantly shorter time-to-death among the untreated LPS group compared to the DA (50 U/kg)-treated LPS group $(p<0.05)$.

\section{Effect of DA on lung tissue specimens}

In the negative control group, no histological alterations were observed (Figure 2a,d,g). Among the LPS group with sepsis, the microscopic changes in the lung tissue specimens observed $12 \mathrm{~h}$ after LPS administration showed oedema-like formation, and interstitial infiltration by neutrophils (Figure $2 b, e, h)$. The interstitial oedema and inflammatory cell infiltration were markedly reduced in the DA-treated group; DA treatment reduced each of these parameters. All of the scores were significantly lower in the DA $(50 \mathrm{U} / \mathrm{kg})$ group than in the LPS group ( $p<0.05$ ) (Figure 3 ). 
Figure 1

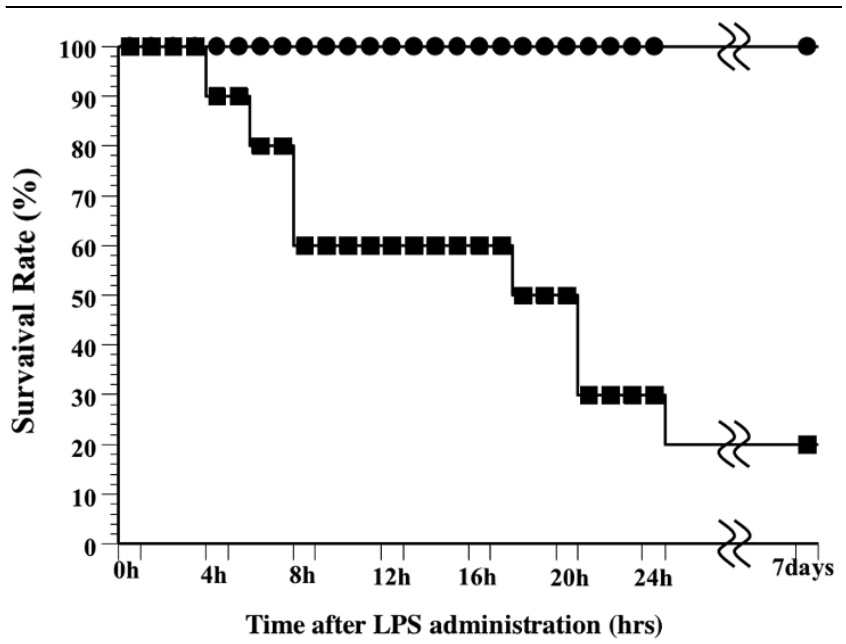

Effect of danaparoid sodium (DA) on the survival rate of lipopolysaccharide (LPS)-treated rats. The survival rate of animals treated with a bolus of LPS $(7.5 \mathrm{mg} / \mathrm{kg})$ into the tail vein (LPS group, $n=10)$ is represented by black squares. The survival rate of animals that received DA $(50 \mathrm{U} / \mathrm{kg})$ in addition to the intravenous injection of LPS $(7.5 \mathrm{mg} / \mathrm{kg})$ into the tail vein (DA treated LPS groups, $n=10$ ) is represented by black circles.
Effects of DA on the serum levels of IL-6, TNF $\alpha, I L-10$ and HMGB1

Prior to LPS administration, IL-6, TNF $\alpha$, IL-10 and HMGB1 in the serum were below levels detectable by the assays. Subsequent to LPS infusion, serum levels of IL-6 increased, with a peak value observed at $3 \mathrm{~h}$ in both groups. Treatment with DA following LPS administration led to a significantly decreased concentration of IL-6 at all assay times $(p<0.05)$ (Figure $4 a$ ). Likewise, serum levels of TNF $\alpha$ peaked $3 \mathrm{~h}$ post-LPS-infusion, with the DA treatment group showing significantly decreased levels at this time point $(p<0.05)$. During the investigation period, TNF $\alpha$ levels of DA-treated LPS group were lower than the LPS group at all assay times (Figure 4b). Serum levels of HMGB1 increased over time following LPS infusion. This increase was less prominent in DA-treated rats compared to the untreated ones. At 6, 9 and $12 \mathrm{~h}$ following LPS administration, HMGB1 was significantly lower in the DA-treated LPS group compared to the untreated LPS group $(p<0.05)$ (Figure $4 \mathrm{c}$ ). By contrast, serum levels of IL-10 peaked $3 \mathrm{~h}$ postLPS-infusion, with the DA-treatment group showing increased levels at all assay times. At 6, 9 and $12 \mathrm{~h}$ following LPS administration, IL-10 was significantly higher in the DA-treated LPS group compared to the untreated LPS group $(p<0.05)$ (Figure 4d).

Figure 2
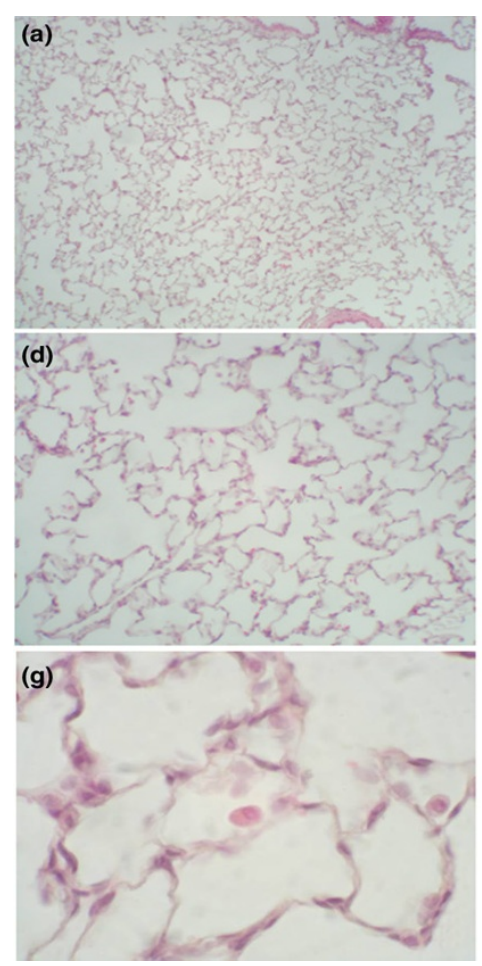
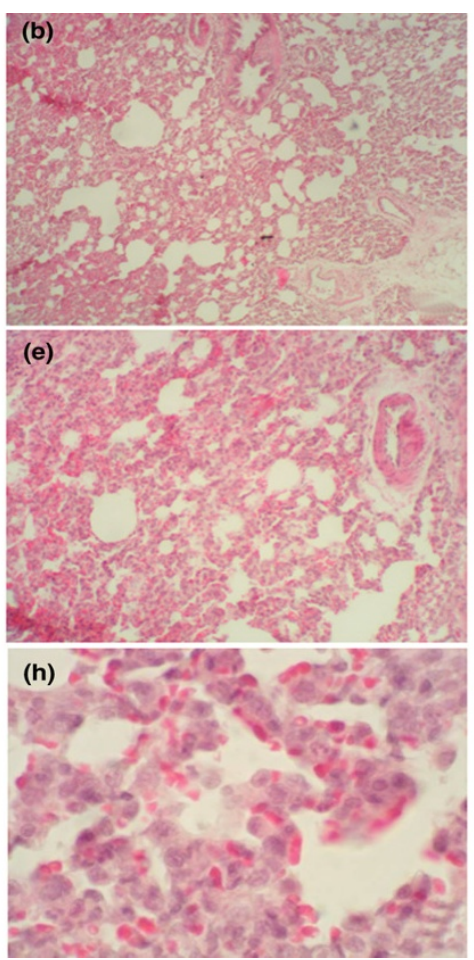
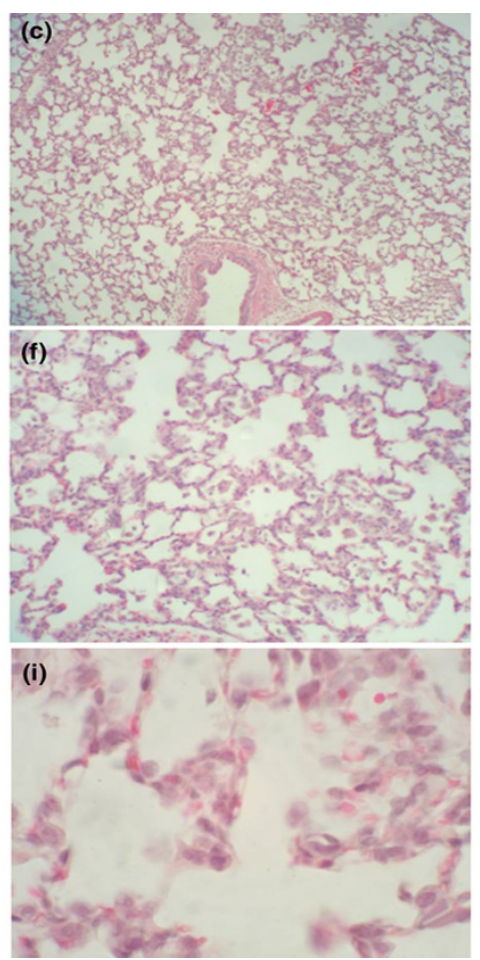

Effects of danaparoid sodium (DA) on lung histopathology in lipopolysaccharide (LPS)-administered rats. Rats were intravenously infused with either saline (control group), $7.5 \mathrm{mg} / \mathrm{kg}$ LPS (LPS group), or $7.5 \mathrm{mg} / \mathrm{kg}$ LPS with $50 \mathrm{U} / \mathrm{kg}$ DA (DA+LPS group). Lung tissue specimens were obtained from the negative control (a) magnification $\times 40$, (d) magnification $\times 100$, (g) magnification $\times 400)$; LPS (b) magnification $\times 40$, (e) magnification $\times 100$, (h) magnification $\times 400$; and DA+LPS (c) magnification $\times 40$, (f) magnification $\times 100$, (i) magnification $\times 400$ groups, respectively. Haematoxylin and eosin staining was used. 
Figure 3

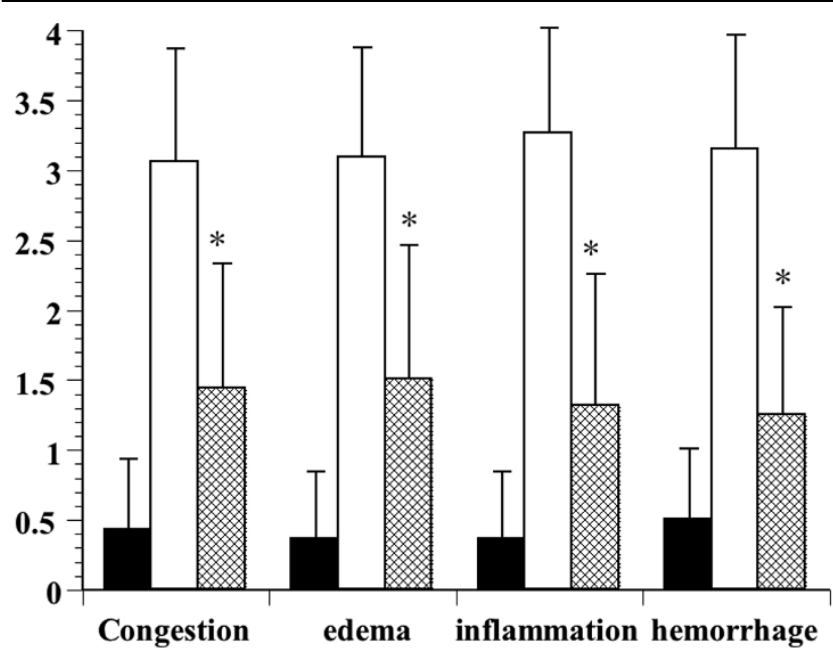

Effects of danaparoid sodium (DA) on lung histopathology score in lipopolysaccharide (LPS)-administered rats. The histological changes identified included congestion, oedema, inflammation, and haemorrhaging $12 \mathrm{~h}$ after the administration of LPS. White bars represent the noninjected control animals, black bars represent the animals injected with LPS, and slashed bars represent animals injected with DA and LPS. The data are expressed as the mean $\pm S D$. *Denotes a significant difference compared with the LPS group $(p<0.05)$.

Effect of DA on the HMGB1 levels in the lung HMGB1 expression in lung tissue increased following LPS injection. This increase was less pronounced among DAtreated rats compared to the untreated LPS group (Figure $5 \mathrm{a}, \mathrm{b})$. In an immunohistochemical analysis, cells expressing HMGB1 increased following LPS administration (Additional file 1a). By contrast, the percentage of cells expressing HMGB1 decreased dramatically in the LPS-administered rats treated with DA (Additional file 1b).

\section{In vitro study}

Effect of DA on the culture supernatant and cell protein of HMGB1

The secretion of HMGB1 was measured in the culture supernatant at $20 \mathrm{~h}$ after the administration of LPS. The HMGB1 level of the culture supernatant increased after the administration of LPS, but the secretion of HMGB1 was inhibited by the administration of DA. In addition, the inhibition of HMGB1 by DA was minimal at a dose of $1 \mathrm{U} / \mathrm{ml}$, was intermediate at a dose of $15 \mathrm{U} / \mathrm{ml}$, and was maximal at a dose of $50 \mathrm{U} / \mathrm{ml}$ (Figure 6). We therefore used a concentration of $50 \mathrm{U} / \mathrm{ml}$ DA for subsequent experiments.

Effect of DA on the culture supernatant of cytokines The TNF $\alpha$ level in the culture supernatant increased $3 \mathrm{~h}$ following the administration of LPS. The administration of DA significantly inhibited the secretion of TNF $\alpha$. The IL- 6 level in the culture supernatant also increased after the administration of LPS. The administration of DA was thus found to significantly inhibit the secretion of IL- 6 in a manner similar to TNF $\alpha$ (Figure 7).

$D A$ inhibits the IKK pathway and modulates NF- $K B$

Since the NF-KB pathway plays a critical role in the secretion of cytokines, we measured the quantity of p50 and p65 in the nucleus. Treatment with LPS led to a robust activation of the NF- $\kappa B$ transcription factor $\mathrm{p} 50 / \mathrm{p} 65$. This activation was partially blocked by DA (Figure 8 ).

We subsequently examined the IKB kinase (IKK) system as another activation agent of NF-KB. Treatment with LPS resulted in the degradation of IKB alpha and this degradation was inhibited by DA (Additional file 2). In addition, the phosphorylation of $p-1 \kappa B$ alpha in RAW264.7 cells increased after LPS administration, and was also inhibited by DA (Additional file 2).

\section{Discussion}

This is the first study to demonstrate the anti-inflammatory actions of DA in a rat model of endotoxin-induced lung injury. Acute inflammatory events, such as those that occur in ALI, lead to dysregulation of the coagulation cascade. Indeed, ALI is characterised by profound alterations in both systemic and intra-alveolar coagulation and fibrinolysis [17]. Activation of coagulation with resultant fibrin deposition also has proinflammatory consequences, serving to further amplify the inflammatory cascade [18]. Lung damage may result not only from the release of inflammatory mediators, but also from coagulation. These results suggest that coagulation and inflammation are related and therefore, anticoagulant therapy, such as treatment with DA, will benefit patients with ALI.

In this study, we demonstrated that treatment with the anticoagulant DA significantly improved acute lung injury and mortality in a rat model. Acute lung injury is characterised by noncardiogenic oedema, pulmonary inflammation and severe systemic hypoxemia. Many sequelae associated with ALI result from excessive production of cytokine mediators (such as TNF $\alpha$ and IL-6) by activated monocytes [19]. In addition, studies have shown that HMGB1 is an important late mediator of inflammation and acute lung injury in sepsis [20-22]. This study adds to the previous findings by suggesting that DA may prevent LPS-induced lung injury by inhibiting cytokine and HMGB1 secretion.

We demonstrated that IL-10 increased following the administration of DA during endotoxin-induced systemic inflammation. A previous study showed that IL-10 inhibited the action of inflammatory cytokines [23] and had profound negative effects on macrophage activation [24]. In particular, IL-10 was closely related to the secretion of TNF $\alpha$ [25]. IL-10 has been identified in the lungs of patients with ARDS, where it was correlated with improved survival [26]. Based on our results, the inhibition of cytokines and prevention of lung injury might be related to 

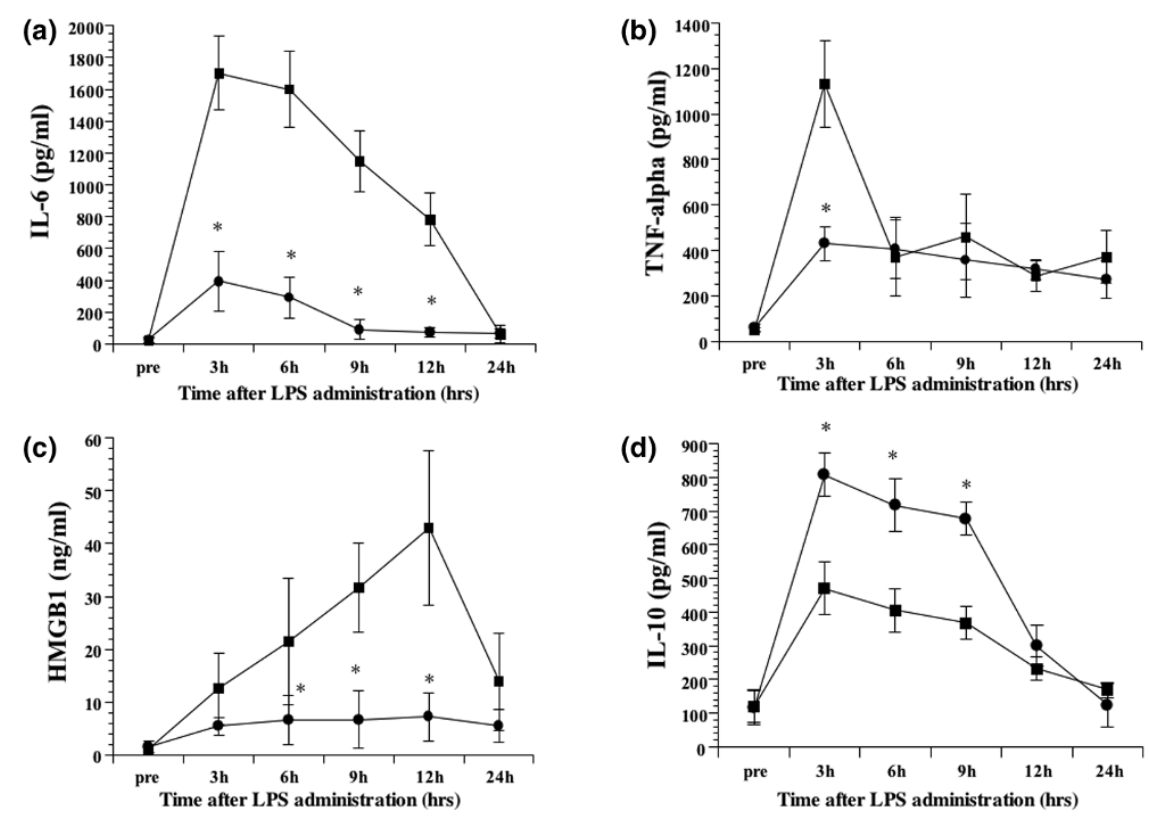

Temporal changes in the tumour necrosis factor (TNF) $\alpha$, interleukin (IL)-6, IL-10, and high mobility group box 1 (HMGB1) serum concentrations following LPS administration. The IL-6 (a), TNF $\alpha$ (b), HMGB1 (c) and IL-10 (d) serum concentrations at the indicated times are shown for the lipopolysaccharide (LPS) $(n=6$; squares) and danaparoid sodium (DA)-treated $(n=6$; circles) groups. All data are expressed as mean \pm SD. *Denotes a significant difference compared with the LPS group $(p<0.05)$.

increased serum levels of IL-10 resulting from administration of DA at LPS-induced systemic inflammation.

NF- $\kappa$ B-dependent genes are related to the development of septic shock and to septic lethality. Studies using an LPS model of septic shock have consistently demonstrated that blocking the NF- $\kappa B$ pathway improves outcome $[27,28]$. Following LPS stimulation, NF- $\kappa B$ is phosphorylated and coordinates the induction of several genes encoding the production and secretion of pro-inflammatory cytokines [29]. Therefore, inhibiting NF- $\kappa B$ activation is crucial for treating inflammation. Here, we showed that DA inhibits LPS-induced NF- $\kappa B$ activation, and may in turn inhibit the secretion of inflammatory mediators and improve survival rate.

Recent studies have demonstrated that coagulation, particularly the generation of thrombin, FXa, and the tissue factorfactor VIla complex, is related to acute inflammatory responses [30]. Indeed, Riewald $\mathrm{M}$ et al., reported that $\mathrm{FXa}$ activates NF- $\mathrm{B}$ [31]. DA is a strong inhibitor of $F X$. Binding of DA to AT III leads to an accelerated inhibition of FXa, resulting in the antithrombotic effect of DA. [32]. These results suggest that the inhibitory effects of DA on NF- $\kappa B$ may be partially due to inhibition of FXa. Further studies are needed to clarify the signalling mechanisms that mediate the beneficial anti-inflammatory effects of DA.

Recent studies have elucidated how LPS is recognised by monocytes and macrophages of the innate immune system.
LPS stimulation of murine macrophages activates several intracellular signalling pathways, including the $I \kappa B$ kinase (IKK)-NF- $\kappa B$ pathway [33,34]. We used a murine macrophage cell line to show that DA suppresses the activation of $N F-\kappa B$ by preventing the phosphorylation of $I \kappa B$. Accordingly, the inhibition of $I \kappa B$ phosphorylation following $D A$ administration in sepsis may lead to the inhibition of NF- $\kappa B$ activation. As a limitation of this study, the mechanisms that mediate these effects of DA in the LPS-induced systemic inflammatory model are not understood, and we need to further investigate the mechanisms of DA on the inhibition of $\mathrm{NF}-\kappa \mathrm{B}$ activation.

\section{Materials and methods}

Antibodies to phosphorylated $\mathrm{lkB}$ and $\mathrm{lkB}$-alpha were obtained from Cell Signaling Technology (Beverly, MA).

\section{Immunohistochemical analysis}

Immunohistochemistry was performed after blocking endogenous peroxidase activity. Blocked sections were incubated with anti-HMGB1 polyclonal antibody (1:1000 dilution). Primary antibody binding was visualized with horseradish peroxidase conjugate and diaminobenzidine.

\section{Western blotting}

Proteins were subjected to sodium dodecyl sulfate-polyacrylamide gel electrophoresis (SDS-PAGE), and then transferred to polyvinylidene difluoride membranes (Millipore, Bedford. MA.). The membranes were incubated with primary antibody 
Figure 5

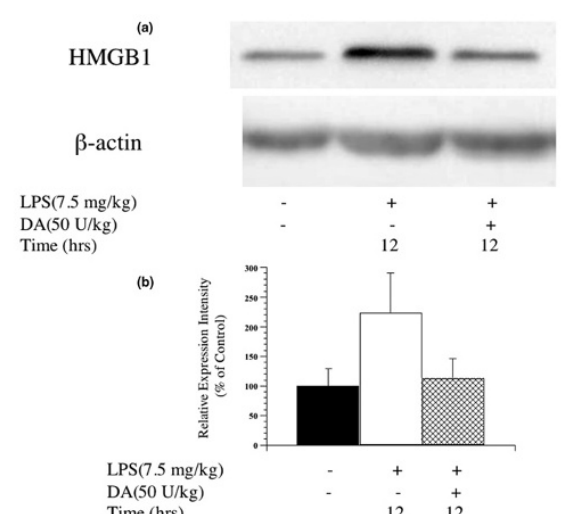

Changes in high mobility group box 1 (HMGB1) protein expression in lung tissue after lipopolysaccharide (LPS) administration in rats. (a) The expression of HMGB1 protein in the lung $12 \mathrm{~h}$ following administration of LPS in untreated LPS and danaparoid sodium (DA)-treated LPS groups was detected by Western blot. Representative blots from three separate experiments are shown. (b) Signal intensities for HMGB1 expression in lung tissue were quantified using an image analyser. Black bars represent the negative control group, white bars represent the LPS group, mesh bars represent the DA-treated LPS group. The expression intensity of HMGB1 protein relative to that of the negative control group was calculated for each group.

(1:1000 dilution). After incubation with secondary antibody, blots were developed using an enhanced chemiluminescence detection kit (Amersham, Buckinghamshire, UK) and exposed on Hyperfilm ECL (Amersham, Buckinghamshire, UK).

Figure 6

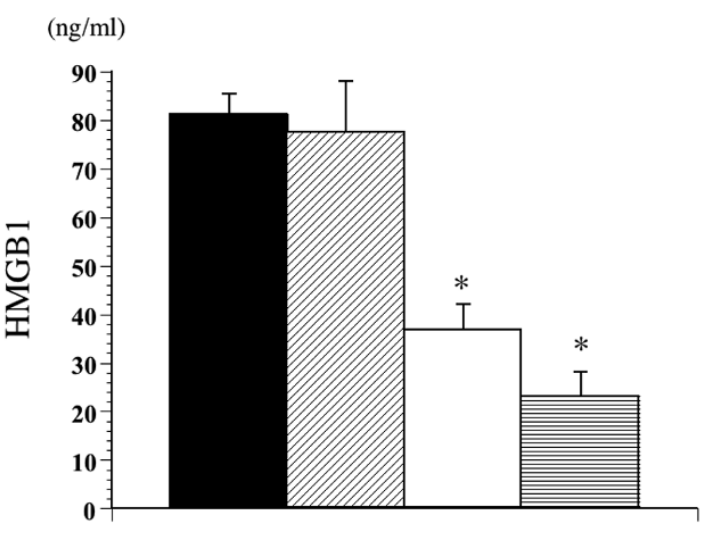

$\begin{array}{lcccc}\text { LPS } & + & + & + & + \\ \text { DA (U/ml) } & - & 1 & 15 & 50 \\ \text { Time (hour) } & 20 & 20 & 20 & 20\end{array}$

Effect of danaparoid sodium (DA) on high mobility group box 1 (HMGB1) production by lipopolysaccharide (LPS)-stimulated murine macrophages. Murine macrophages treated without or with DA $(1,15$, $50 \mathrm{U} / \mathrm{ml})$ were stimulated with LPS $(100 \mathrm{ng} / \mathrm{ml})$ for $20 \mathrm{~h}$. Supernatants and cell protein were prepared and examined by enzyme linked immunosorbent assay (ELISA). All data are expressed as means \pm SD. *Denotes a significant difference compared with the LPS group $(p<$ 0.05).
Figure 7

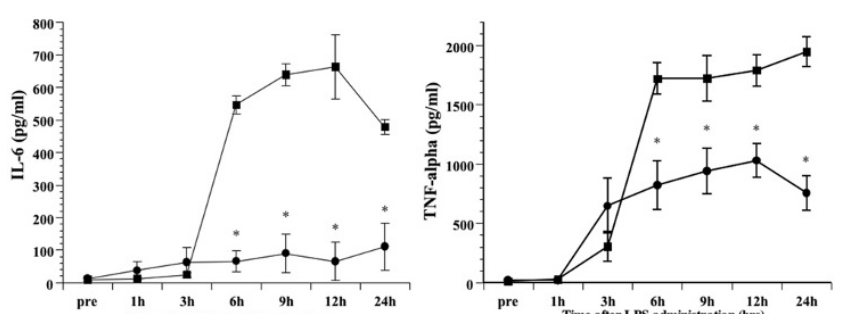

Effect of danaparoid sodium (DA) on interleukin (IL)-6 and tumour necrosis factor (TNF) $\alpha$ production by lipopolysaccharide (LPS)-stimulated murine macrophages. Murine macrophages treated with or without DA $(50 \mathrm{U} / \mathrm{ml})$ were stimulated with LPS $(100 \mathrm{ng} / \mathrm{ml})$ for the indicated time. Supernatants were collected and IL- 6 and TNF $\alpha$ levels were determined by enzyme linked immunosorbent assay (ELISA). All data are expressed as mean $\pm S D$. *Denotes a significant difference compared with the LPS-treated cells $(p<0.05)$.

\section{Conclusion}

Using an LPS-induced systemic inflammation model in rats, we demonstrated that danaparoid sodium $(50 \mathrm{U} / \mathrm{kg}$ ) can reduce pulmonary histopathology, decrease mortality, and diminish systemic inflammatory mediators. To our knowledge, this is the first in vivo study that has shown such an effect. In a companion tissue culture experiment, we also demonstrated that LPS-induced secretion of cytokines can be decreased by inhibiting the IKK system. Our results suggest that DA may play a role in reducing the pathology of systemic inflammation, and that the potential mechanism of action is through the adjustment of various inflammatory mediators. Given our results, it is possible that DA may have a therapeutic effect on

\section{Figure 8}

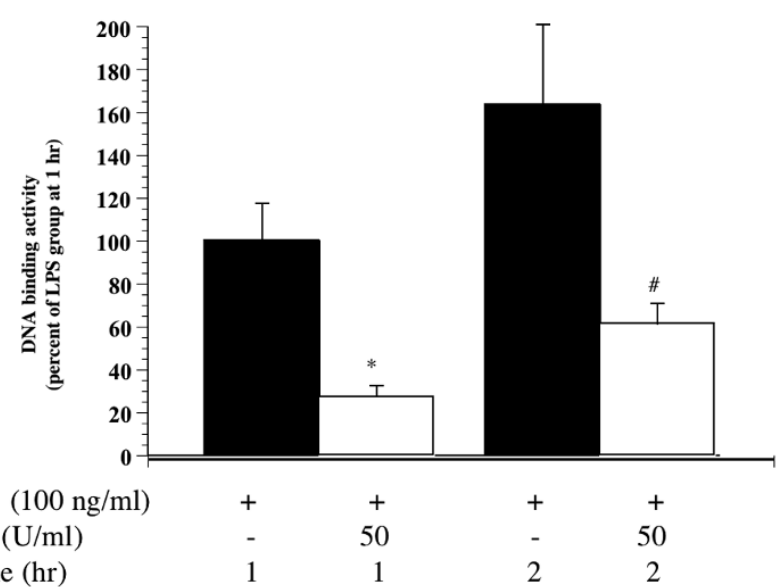

Effect of danaparoid sodium (DA) on the lipopolysaccharide (LPS)induced increase of $p 50 / p 65$ binding to DNA. The DNA binding activity assay showed a marked decrease in the p50/p65 binding activity in nuclear fractions from RAW264.7 cells. All data are expressed as the mean \pm SD. *Denotes a significant difference compared with LPS group at $1 \mathrm{~h}(\mathrm{p}<0.05)$. \#Denotes a significant difference compared with LPS group at $2 \mathrm{~h}(\mathrm{p}<0.05)$. 
patients with systemic inflammation, such as septic shock, ARDS, and so on. DA has low toxicity and it is approved for the treatment of systemic inflammatory diseases.

\section{Competing interests}

The authors declare that they have no competing interests.

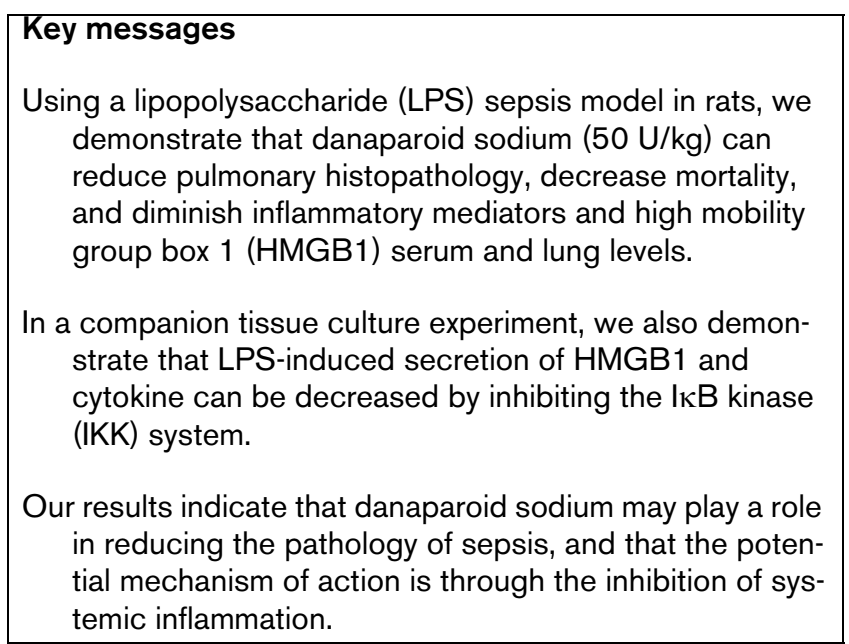

\section{Authors' contributions}

$\mathrm{SH}$ participated in the study design, performed animal, cell culture, biochemical and histological studies, and drafted the manuscript. $\mathrm{HI}$ planned the experimental design and performed biochemical and histological studies. SH participated in the study design and performed animal studies. $\mathrm{SH}$ performed animal, cell culture study and biochemical analysis. TN participated in the study design, helped to draft the manuscript and coordinated the research group. All authors read and approved the final manuscript.

\section{Additional files}

The following Additional files are available online:

\section{Additional file 1}

Changes in the HMGB1 protein expression in lung tissue specimens after LPS administration in rats. (A) Immunohistochemcal analysis to detect HMGB1 in lung from animals killed twelve hours after $7.5 \mathrm{mg} / \mathrm{kg}$ LPS intravenous administration. The arrows indicate cells stained positive for HMGB1; $\times 400$. (B) An immunohistochemical analysis to detect HMGB1 in the lung from animals treated with 50 units $/ \mathrm{kg}$ DA and killed twelve hours after $20 \mathrm{mg} / \mathrm{kg}$ LPS intravenous administration; $\times 400$.

See http://www.biomedcentral.com/content/ supplementary/cc6851-S1.tiff

\section{Additional file 2}

Effect of DA on the LPS-induced phosphorylation of lkB. Murine macrophages treated with or without DA (50 units $/ \mathrm{ml}$ ) were stimulated with LPS $(100 \mathrm{ng} / \mathrm{ml})$ for $1 \mathrm{hr}$. The cytoplasmic levels of phosphorylated lkB were determined by Western blot analysis using phosphorylated IkB alpha, IkB alpha, and beta-actin antibodies. Representative blots from three separate experiments are shown.

See http://www.biomedcentral.com/content/ supplementary/cc6851-S2.tiff

\section{Acknowledgements}

The authors wish to thank Dr Tomohisa Uchida for his thoughtful comments and for scoring the lung specimens.

\section{References}

1. Ware LB, Matthay MA: The acute respiratory distress syndrome. N Engl J Med 2000, 342:1334-1349.

2. Bhatia M, Moochhala S: Role of inflammatory mediators in the pathophysiology of acute respiratory distress syndrome. J Pathol 2004, 202:145-156.

3. Ghosh S, Latimer RD, Gray BM, Harwood RJ, Oduro A: Endotoxin-induced organ injury. Crit Care Med 1993, 21:S19-24.

4. Bustin M: Regulation of DNA-dependent activities by the functional motifs of the high-mobility-group chromosomal proteins. Mol Cell Biol 1999, 19:5237-5246.

5. Wang $\mathrm{H}$, Bloom $\mathrm{O}$, Zhang $\mathrm{M}$, Vishnubhakat JM, Ombrellino $\mathrm{M}$, Che J, Frazier A, Yang H, Ivanova S, Borovikova L, Manogue KR, Faist $\mathrm{E}$, Abraham E, Andersson J, Andersson U, Molina PE, Abumrad NN, Sama A, Tracey KJ: HMG-1 as a late mediator of endotoxin lethality in mice. Science 1999, 285:248-251.

6. Fiuza C, Bustin M, Talwar S, Tropea M, Gerstenberger E, Shelhamer $\mathrm{JH}$, Suffredini AF: Inflammation-promoting activity of HMGB1 on human micro vascular endothelial cells. Blood 2003, 101:2652-2660.

7. Park JS, Gamboni-Robertson F, He Q, Svetkauskaite D, Kim JY, Strassheim D, Sohn JW, Yamada S, Maruyama I, Banerjee A, Ishizaka A, Abraham E: High Mobility Group Box 1 protein (HMGB1) interacts with multiple Toll like receptors. $A m \mathrm{~J}$ Physiol Cell Physiol 2006, 290:917-924.

8. Kokkola R, Andersson A, Mullins G, Ostberg T, Treutiger CJ Arnold B, Nawroth $P$, Andersson U, Harris RA, Harris HE: RAGE is the major receptor for the proinflammatory activity of HMGB1 in rodent macrophages. Scand J Immunol 2005, 61:1-9.

9. Iba T, Kidokoro A, Yagi $Y$ : The role of the endothelium in changes in procoagulant activity. J Am Coll Surg 1998, 87:321-329.

10. Macfarlane SR, Seatter MJ, Kanke T, Hunter GD, Plevin R: Proteinase-activated receptors. Pharmacol Rev 2001, 53:245-282.

11. Meuleman DG: Orgaran (Org10172): its pharmacological profile in experimental models. Haemostasis 1992, 22:58-65.

12. Iba T, Kidokoro A, Fukunaga M, Fuse S, Suda M, Kunitada S, Hara T: Factor Xa-inhibitor (DX-9065a) modulates the leukocyteendothelial cell interaction in endotoxemic rat. Shock 2002, 17:159-162.

13. Iba T, Kidokoro A, Fukunaga M, Nagakari K, Suda M, Yoshikawa S, Ida Y: Antithrombin ameliorates endotoxin-induced organ dysfunction more efficiently when combined with danaparoid sodium than with unfractionated heparin. Intensive Care Med 2005, 31:1101-1108.

14. Freeman BD, Zehnbauer BA, Buchman TG: A meta-analysis of controlled trials of anticoagulant therapies in patients with sepsis. Shock 2003, 20:5-9.

15. Matthay MA: Severe sepsis: a new treatment with both anticoagulant and anti-inflammatory properties. N Engl J Med 2001, 344:759-762. 
16. Murakami K, McGuire R, Cox RA, Jodoin JM, Bjertnaes $L$, Katahira J, Traber LD, Schmalstieg FC, Hawkins HK, Herndon DN, Traber DL: Heparin nebulization attenuates acute lung injury in sepsis following smoke inhalation in sheep. Shock 2002, 18:236-241.

17. Schultz MJ, Haitsma JJ, Zhang H, Slutsky AS: Pulmonary coagulopathy as a new target in therapeutic studies of acute lung injury or pneumonia - a review. Crit Care Med 2006, 34:871-877.

18. Feistritzer C, Wiedermann CJ: Effects of anticoagulant strategies on activation of inflammation and coagulation. Expert Opin Biol Ther 2007, 7:855-870.

19. Ward PA: Role of complement, chemokines, and regulatory cytokines in acute lung injury. Ann NY Acad Sci 1996, 796:104-112.

20. Yang $\mathrm{H}$, Wang $\mathrm{H}$, Tracey $\mathrm{KJ}$ : HMG-1 rediscovered as a cytokine. Shock 2001, 15:247-253

21. Ueno H, Matsuda T, Hashimoto S, Amaya F, Kitamura Y, Tanaka M, Kobayashi A, Maruyama I, Yamada S, Hasegawa N, Soejima J, Koh $\mathrm{H}$, Ishizaka A: Contributions of high mobility group box protein in experimental and clinical acute lung injury. Am J Respir Crit Care Med 2004, 170:1310-1316.

22. Angus DC, Yang L, Kong L, Kellum JA, Delude RL, Tracey KJ, Weissfeld L, GenIMS Investigators: Circulating high-mobility group box 1 (HMGB1) concentrations are elevated in both uncomplicated pneumonia and pneumonia with severe sepsis. Crit Care Med 2007, 35:1061-1067.

23. Fiorentino DF, Zlotnik A, Mosmann TR, Howard M, O'Garra A: IL10 inhibits cytokine production by activated macrophages. J Immunol 1991, 147:3815-3822.

24. O'Farrell AM, Liu Y, Moore KW, Mui AL: IL-10 inhibits macrophage activation and proliferation by distinct signaling mechanisms: evidence for Stat3-dependent and -independent pathways. EMBO J 1998, 17:1006-1018.

25. Bogdan $C$, Vodovotz $Y$, Nathan C: Macrophage deactivation by interleukin-10. J Exp Med 1991, 174:1549-1555.

26. Donnelly SC, Strieter RM, Reid PT, Kunkel SL, Burdick MD, Armstrong I, Mackenzie A, Haslett C: The association between mortality rates and decreased concentrations of interleukin-10 and interleukin-1 receptor antagonist in the lung fluids of patients with the adult respiratory distress syndrome. Ann Intern Med 1996, 125:191-196.

27. Sheehan $M$, Wong $H$, Hake PW, Malhotra V, O'Connor M, Zingarelli $B$ : Parthenolide, an inhibitor of the nuclear factor-kappaB pathway, ameliorates cardiovascular derangement and outcome in endotoxic shock in rodents. Mol Pharmacol 2002, 61:953-963.

28. Kang YJ, Seo SJ, Yun-Choi HS, Lee DH, Kim YM, Chang KC: A synthetic isoquinoline alkaloid, 1-(beta-naphthylmethyl)-6,7dihydroxy-1,2,3,4-tetrahydroisoquinoline (YS 51), reduces inducible nitric oxide synthase expression and improves survival in a rodent model of endotoxic shock. J Pharmacol Exp Ther 2002, 301:561-567.

29. Adcock IM: Transcription factors as activators of gene transcription: AP-1 and NF-kappa B. Monaldi Arch Chest Dis 1997, 52:178-186.

30. Esmon CT: Role of coagulation inhibitors in inflammation. Thromb Haemost 2001, 86:51-56.

31. Riewald M, Kravchenko VV, Petrovan RJ, O'Brien PJ, Brass LF, Ulevitch RJ, Ruf W: Gene induction by coagulation factor $\mathrm{Xa}$ is mediated by activation of protease-activated receptor 1 . Blood 2001, 97:3109-3116.

32. Skoutakis VA: Danaparoid in the prevention of thromboembolic complications. Ann Pharmacother 1997, 31:876-887.

33. Kwak HJ, Song JS, Heo JY, Yang SD, Nam JY, Cheon HG: Roflumilast inhibits lipopolysaccharide-induced inflammatory mediators via suppression of nuclear factor-kappaB, p38 mitogen-activated protein kinase, and c-Jun NH2-terminal kinase activation. J Pharmacol Exp Ther 2005, 315:1188-1195.

34. Schottelius AJ, Mayo MW, Sartor RB, Baldwin AS: Interleukin-10 signaling blocks inhibitor of kappaB kinase activity and nuclear factor kappaB DNA binding. J Biol Chem 1999, 274:31868-31874. 